ASTHMA

\title{
Bronchial mucosal inflammation and upregulation of CXC chemoattractants and receptors in severe exacerbations of asthma
}

\author{
Yusheng Qiu, Jie Zhu, Venkata Bandi, Kay K Guntupalli, Peter K Jeffery
}

Thorax 2007;62:475-482. doi: 10.1136/thx.2006.066670

See end of article for authors' affiliations

Correspondence to: Professor Peter K Jeffery, Lung Pathology, Royal Brompton Hospital, Sydney Street, London SW3 6NP,

UK; p.jeffery@ic.ac.uk

Received 7 June 2006

Accepted 11 November 2006

Published Online First

17 January 2007
Background: A study was undertaken to test the hypothesis that severe exacerbations of asthma are characterised by increased bronchial mucosal neutrophilia associated with upregulation of neutrophil chemoattractant ligands and their specific cell surface receptors.

Methods: Immunohistology and in situ hybridisation were applied to endobronchial biopsy specimens from three groups: (1) 15 patients admitted to hospital with a severe exacerbation of asthma (E-asthma), (2) 15 with stable asthma (S-asthma) and (3) 15 non-atopic and non-smoker surgical controls (NSC).

Results: There were significantly more neutrophils and eosinophils in the epithelium and subepithelium of patients in the E-asthma group (median (range) neutrophils $7(0-380)$ and $78(10-898) / \mathrm{mm}^{2}$, eosinophils $31(0-167)$ and $60(6-351) / \mathrm{mm}^{2}, \mathrm{p} \leqslant 0.01$ compared with NSC: $0(0-10,0-7,0-18$ and $0-3) / \mathrm{mm}^{2}$, respectively), resulting in similar final densities of eosinophils and neutrophils. With respect to neutrophil chemoattractants and receptors, counts of CXCL5, CXCL8, CXCR1 and CXCR2 mRNA-positive cells in the subepithelium of the E-asthma group were, respectively, 5, 4, 4 and 18 times greater $(p \leqslant 0.01)$ than those of the NSC group. In the E-asthma group, cells expressing CXCL5 or CXCR2 were eightfold and threefold more frequent than those expressing CXCL8 or CXCR1 mRNA, respectively $(p<0.01)$. CXCL5 and CXCR2 in Easthma were associated with the number of eosinophils ( $r=0.59$ and $0.66, p<0.02$ for both) rather than the number of neutrophils.

Conclusion: In severe exacerbations of asthma there is a bronchial mucosal neutrophilia, eosinophilia and upregulation of CXC chemoattractants and their receptors. CXCL5 and CXCR2 have an association with eosinophila only, and these represent potentially new targets for treatment in exacerbations of asthma.
A cute severe exacerbations of asthma are life-threatening medical emergencies that contribute substantially to the costs of health care. ${ }^{1}$ Research and direct examination of tissue, where ethical and possible, is helpful in the recognition of exacerbation-specific targets which may assist in the development of new treatments aimed at reducing exacerbation frequency and length, improving quality of life and reducing asthma-associated mortality.

In comparison with normal healthy tissue, in stable asthma there is an accumulation of $\mathrm{CD} 4+\mathrm{T}$ (helper) lymphocytes, eosinophils and mast cells in the airway mucosa. ${ }^{2-4}$ However, neutrophilic inflammation increases in severe disease and in mild exacerbations of asthma..$^{5-10}$ The predominant patterns of inflammation that exist in stable asthma therefore become less clear in severe exacerbations of asthma. In particular, the increased recruitment of neutrophils to the airway mucosa indicates that neutrophils can become major effector cells.

Neutrophil accumulation in tissue is partly a result of chemoattraction by neutrophil chemokines including interleukin-8 (also known as CXCL8) and epithelial-derived neutrophil attractant-78 (also known as CXCL5) via actions on cell surface receptors, specifically CXCR1 and CXCR2. ${ }^{11-14}$ In severe exacerbations of chronic obstructive pulmonary disease (COPD), neutrophil recruitment to the bronchial mucosa occurs which is associated with upregulation of CXCL5, CXCL8 and receptors CXCR1 and CXCR2. ${ }^{15}$ Similar studies of bronchial tissue obtained from patients with asthma who experience exacerbations sufficiently severe to require admission to hospital have not previously been reported. We have therefore tested the hypothesis that mechanisms similar to those responsible for the infiltration of the bronchial mucosa by neutrophils in severe exacerbations of COPD also occur when there is a neutrophilia associated with severe exacerbations of asthma.

In patients with asthma who experienced a severe exacerbation, the numbers of neutrophils and eosinophils recruited to the airway mucosa and the numbers of cells expressing genes for the receptors CXCR1 and CXCR2 and their chemokine ligands CXCL5, CXCL8 were determined. The cell counts in the bronchial mucosa of patients with severe exacerbations of asthma were compared with those from patients with stable asthma and with non-atopic non-smoker controls.

\section{METHODS}

Study subjects

The study setting for the analysis of all biopsies was Imperial College London at the Royal Brompton Hospital, London, UK. Most of the tissues had been sectioned and used for a previously published study. ${ }^{16}$ With permission from the study participants, additional sections were used for staining and comparisons made herein. Those with severe exacerbations and the non-smoker surgical controls were recruited at Ben Taub General Hospital, Houston, Texas, USA. The subjects with mild asthma had been recruited previously from other centres including the UK. The study conformed to the Declaration of Helsinki. Approval for analysis of the tissues for inflammatory cells and receptors was given by each of the local institutional review boards for human studies. Each subject or, in the case of

Abbreviations: COPD, chronic obstructive pulmonary disease; EG2, antieosinophil cationic protein; $\mathrm{FEV}_{1}$, forced expiratory volume in $1 \mathrm{~s}$; FVC, forced vital capacity; NE, neutrophil elastase; RBM, reticular basement membrane 
Table 1 Clinical characteristics of patients with an asthma exacerbation, patients with stable asthma and non-atopic non-smoker controls

\begin{tabular}{|c|c|c|c|c|c|c|}
\hline \multirow[b]{2}{*}{ Subject no } & \multirow[b]{2}{*}{ Sex } & \multirow[b]{2}{*}{$\begin{array}{l}\text { Age } \\
\text { (years) }\end{array}$} & \multirow[b]{2}{*}{$\begin{array}{l}\mathrm{FEV}_{1} \\
\text { (\% pred) }\end{array}$} & \multirow[b]{2}{*}{$\begin{array}{l}\mathrm{FEV}_{1} / \mathrm{FVC} \\
(\%)\end{array}$} & \multicolumn{2}{|l|}{ Medication } \\
\hline & & & & & $\begin{array}{l}\text { Home inhaled } \\
\mathrm{GC}^{\star *} \text { dose } \\
\text { ( } \mathrm{g} / \text { day) }\end{array}$ & $\begin{array}{l}\text { Home oral } \\
\text { GC dose } \\
\text { (mg/day) }\end{array}$ \\
\hline \multicolumn{7}{|c|}{ E-asthma $(n=15)$} \\
\hline 1 & $\mathrm{~F}$ & 50 & 28 & 32 & 0 & 10 \\
\hline 2 & $\mathrm{~F}$ & 50 & 28 & 32 & 1600 & 0 \\
\hline 3 & M & 51 & 27 & 33 & 1600 & 20 \\
\hline 4 & M & 24 & 18 & 21 & 0 & 10 \\
\hline 5 & $\mathrm{~F}$ & 42 & 40 & 48 & 1600 & 20 \\
\hline 6 & $\mathrm{~F}$ & 62 & 59 & 70 & 600 & 0 \\
\hline 7 & $\mathrm{~F}$ & 53 & 32 & 35 & 1600 & 0 \\
\hline 8 & $\mathrm{~F}$ & 47 & 38 & 54 & 1600 & 0 \\
\hline 9 & $\mathrm{~F}$ & 50 & 49 & 32 & 1600 & 30 \\
\hline 10 & M & 39 & 31 & 37 & 1600 & 20 \\
\hline 11 & $\mathrm{~F}$ & 52 & 41 & 38 & 800 & 0 \\
\hline 12 & $\mathrm{~F}$ & 74 & 60 & 47 & 1600 & 0 \\
\hline 13 & $\mathrm{~F}$ & 64 & 56 & 42 & 1600 & 20 \\
\hline 14 & M & 47 & 41 & 39 & 1600 & 30 \\
\hline 15 & $\mathrm{~F}$ & 56 & 52 & 45 & 0 & 0 \\
\hline Mean & & $50.7 \dagger$ & $40^{*} \dagger$ & $40.3^{*}+$ & & \\
\hline SE & & 2.9 & 3.3 & 3.0 & & \\
\hline \multicolumn{7}{|c|}{ S-asthma $(n=15)$} \\
\hline 16 & $\mathrm{~F}$ & 39 & 93 & 73 & $0 \ddagger$ & $0 \ddagger$ \\
\hline 17 & M & 25 & $76 \S$ & 85 & $0 \ddagger$ & $0 \ddagger$ \\
\hline 18 & M & 40 & 92 & 81 & $0 \ddagger$ & $0 \ddagger$ \\
\hline 19 & $M$ & 25 & 95 & 72 & $0 \ddagger$ & $0 \ddagger$ \\
\hline 20 & $\mathrm{~F}$ & 24 & 89 & 78 & $0 \ddagger$ & $0 \ddagger$ \\
\hline 21 & $\mathrm{~F}$ & 25 & 84 & 97 & $0 \ddagger$ & $0 \ddagger$ \\
\hline 22 & $\mathrm{~F}$ & 26 & 97 & 76 & $0 \ddagger$ & $0 \ddagger$ \\
\hline 23 & $\mathrm{~F}$ & 25 & 97 & 91 & $0 \ddagger$ & $0 \neq$ \\
\hline 24 & $\mathrm{~F}$ & 26 & 88 & 82 & $0 \ddagger$ & $0 \ddagger$ \\
\hline 25 & $\mathrm{~F}$ & 20 & 80 & 82 & $0 \ddagger$ & $0 \neq$ \\
\hline 26 & $M$ & 27 & 72 & 81 & $0 \ddagger$ & $0 \ddagger$ \\
\hline 27 & $\mathrm{~F}$ & 38 & 97 & 80 & $0 \ddagger$ & $0 \ddagger$ \\
\hline 28 & $\mathrm{~F}$ & 23 & 85 & 91 & $0 \ddagger$ & $0 \ddagger$ \\
\hline 29 & $\mathrm{~F}$ & 22 & 86 & 87 & $0 \ddagger$ & $0 \ddagger$ \\
\hline 30 & $\mathrm{~F}$ & 39 & 82 & 70 & $0 \ddagger$ & $0 \ddagger$ \\
\hline Mean & & $28^{*}$ & $87^{*}$ & 82 & & \\
\hline $\mathrm{SE}$ & & 1.8 & 7.8 & 7.6 & & \\
\hline \multicolumn{7}{|l|}{ NSC $(n=15)$} \\
\hline 31 & $\mathrm{~F}$ & 42 & 112 & 81 & 0 & 0 \\
\hline 32 & M & 45 & 95 & 78 & 0 & 0 \\
\hline 33 & $\mathrm{~F}$ & 62 & 94 & 76 & 0 & 0 \\
\hline 34 & $\mathrm{~F}$ & 41 & 98 & 79 & 0 & 0 \\
\hline 35 & $\mathrm{~F}$ & 52 & 89 & 82 & 0 & 0 \\
\hline 36 & $\mathrm{~F}$ & 42 & 90 & 79 & 0 & 0 \\
\hline 37 & $\mathrm{~F}$ & 44 & 106 & 81 & 0 & 0 \\
\hline 38 & $\mathrm{~F}$ & 52 & 89 & 82 & 0 & 0 \\
\hline 39 & $\mathrm{~F}$ & 41 & 97 & 81 & 0 & 0 \\
\hline 40 & $\mathrm{~F}$ & 37 & 103 & 78 & 0 & 0 \\
\hline 41 & M & 42 & 108 & 80 & 0 & 0 \\
\hline 42 & $\mathrm{~F}$ & 53 & 90 & 79 & 0 & 0 \\
\hline 43 & $\mathrm{~F}$ & 57 & 102 & 84 & 0 & 0 \\
\hline 44 & $\mathrm{~F}$ & 42 & 93 & 79 & 0 & 0 \\
\hline 45 & $\mathrm{~F}$ & 48 & 103 & 84 & 0 & 0 \\
\hline Mean & & 47 & 98 & 80 & & \\
\hline SE & & 1.5 & 1.6 & 0.8 & & \\
\hline
\end{tabular}

E-asthma, patients with asthma with an acute severe exacerbation; S-asthma, patients with stable asthma; NSC, nonsmoking surgical controls; GC, glucocorticoid.

Time line for $\mathrm{FEV} 1$ measurements: $\mathrm{E}$-asthma, after liberation from the mechanical ventilator and before discharge from hospital; S-asthma and NSC controls, before bronchoscopy.

*p $<0.0001$ vs NSC.

$\mathrm{tp}<0.0001$ vs S-asthma.

$\ddagger$ None before 3 months of the start of the study.

$\$ \mathrm{PC}_{20}$ value 0.02326 .

- $P C_{20}$ value 0.04073

${ }^{* *}$ Triamcinolone acetonide. 
intubated patients, their surrogates, gave informed written consent.

There were three subject groups, all of whom were nonsmokers, who had been examined and reported previously: ${ }^{16}$

- patients with asthma with an acute severe exacerbation (Easthma; $\mathrm{n}=15$ );

- patients with stable asthma ( $S$-asthma; $\mathrm{n}=15$ );

- non-smoking surgical controls (NSC; $\mathrm{n}=15$ ).

\section{Patients with asthma with an acute severe} exacerbation (E-asthma)

These patients were admitted to hospital and intubated for clinical reasons. However, endobronchial biopsy specimens were taken for the purposes of research. They had had asthma symptoms for a mean (SE) of $21.2(2.2)$ years (range 8-40) and had experienced one of the following features: continuous symptoms, frequent exacerbations or night-time asthma symptoms, peak expiratory flow (PEF) or forced expiratory volume in $1 \mathrm{~s}\left(\mathrm{FEV}_{1}\right) \leqslant 60 \%$ predicted, $\mathrm{FEV}_{\mathrm{l}} /$ forced vital capacity (FVC) ratio $<70 \%$ and variability $\geqslant 30 \%$. The patients met the criteria for the definition of a severe exacerbation, that is, a sudden worsening of asthma symptoms (wheezing, breathlessness, chest tightness and cough) and lung function requiring emergency admission to hospital. ${ }^{17}$ They were admitted to the ICU for status asthmaticus and respiratory failure. Once stabilised, they were recruited into the study. Approximately $70 \%$ of the surrogates approached consented. These patients were on $\beta_{2}$-agonist nebuliser and received 1-3 doses of corticosteroids (Solumedrol 60-80 mg/6-12 h) and l-2 doses of antibiotics intravenously during the admission, prior to biopsy. They were also receiving multiple daily controller medication before the exacerbation and had received shortacting $\beta_{2}$-agonist as required. Twelve of the 15 subjects in this group had previously been receiving inhaled steroids (triamcinolone acetonide) and 8 had received oral steroids. Skin tests to a panel of common allergen extracts showed that 9 were atopic, 4 were non-atopic and in 2 cases their atopic status was not tested.

\section{Patients with stable asthma ( $S$-asthma)}

Each subject made a pre-study screening visit in which a full clinical assessment (including spirometric tests, chest radiography, ECG and histamine challenge testing) was undertaken. The diagnosis of asthma was made on the basis of clinical symptoms, peak flow variability, lung function studies with spirometry and bronchoprovocation testing. The patients had had asthma symptoms for a mean (SE) of 14.6 (1.7) years (range 1-37). Each had a clinical history of intermittent asthma, defined clinically using the Global Initiative for Asthma guideline criteria with symptoms less than once a week, brief exacerbations, nocturnal symptoms not more than twice a month and normal lung function between episodes. ${ }^{17}$ Their pre-bronchodilator $\mathrm{FEV}_{1}$ was $\geqslant 70 \%$ predicted and $\mathrm{FEV}_{1} /$ FVC was $>70 \%$. A minimum of 6 weeks since any evidence of infection/exacerbation was required. None of these subjects had any other respiratory illness. They were using short-acting $\beta_{2}$ bronchodilators on an as needed basis and had not received any daily controller medication, inhaled, oral or injected steroids during the previous 3 months. All of the subjects underwent a histamine bronchoprovocation study with $\mathrm{PC}_{20}<4 \mathrm{mg} / \mathrm{ml}$. Subjects 17 and 26 had a reduced $\mathrm{FEV}_{1}$ but with a normal ratio and there was no spirometric evidence of a restrictive lung process.

\section{Non-smoking surgical controls (NSC)}

Non-atopic non-asthmatic subjects scheduled for elective surgical procedures under general anaesthesia for non-bronchopulmonary disease (such as hysterectomy or cholecystectomy) were recruited. These subjects completed a respiratory questionnaire and then underwent spirometry. Subjects were enrolled if they had no upper airway and respiratory symptoms and had normal lung function $\left(\mathrm{FEV}_{1}>80 \%\right.$ predicted and $\left.\mathrm{FEV}_{1} / \mathrm{FVC}>70 \%\right)$. Eighty percent of subjects approached participated in the study. Blood eosinophil counts were within the range $0.0-0.4 \times 10^{9} / \mathrm{l}$. This group also acted as controls for the possible effects of intubation per se (table 1 ).

\section{Bronchoscopy and biopsies}

Patients in the E-asthma group required intubation and underwent bronchoscopy and biopsy within $24 \mathrm{~h}$ of their admission. In the S-asthma group biopsy specimens were taken under sedation and in the NSC group the biopsy specimens were taken immediately after intubation and before the infusion of prophylactic antibiotics. Biopsies were taken using an Olympus type BF P10 or BF P20D (Olympus Co, Tokyo, Japan) with alligator forceps (microvasive radial jaw single use biopsy forceps, $1.8 \mathrm{~mm}$ external diameter (Boston Scientific Corporation, Massachusetts, USA). Three biopsy specimens were taken from each patient, either from the carina of the third, fourth or fifth order bronchial division of the right or left lung. They were fixed immediately in $10 \%$ formaldehyde and embedded in paraffin wax. Serial sections $5 \mu \mathrm{m}$ thick were cut and stained with haematoxylin-eosin (H\&E).

\section{Immunohistochemistry}

Neutrophils and eosinophils were identified using mouse antihuman neutrophil elastase (NE; Dako A/S, Glostrup, Denmark) and anti-eosinophil cationic protein (EG2; Pharmacia \& Upjohn Diagnostics AB, Uppsala, Sweden), both monoclonal antibodies used at 1/100 dilution and visualised with the EnVisionalkaline phosphatase (EV-AP) technique and kit applied according to the manufacturer's instructions (K4017, Dako UK, Cambridge, UK). All immunoprocedures were performed using the Techmate Horizon automated immunostainer (LJL
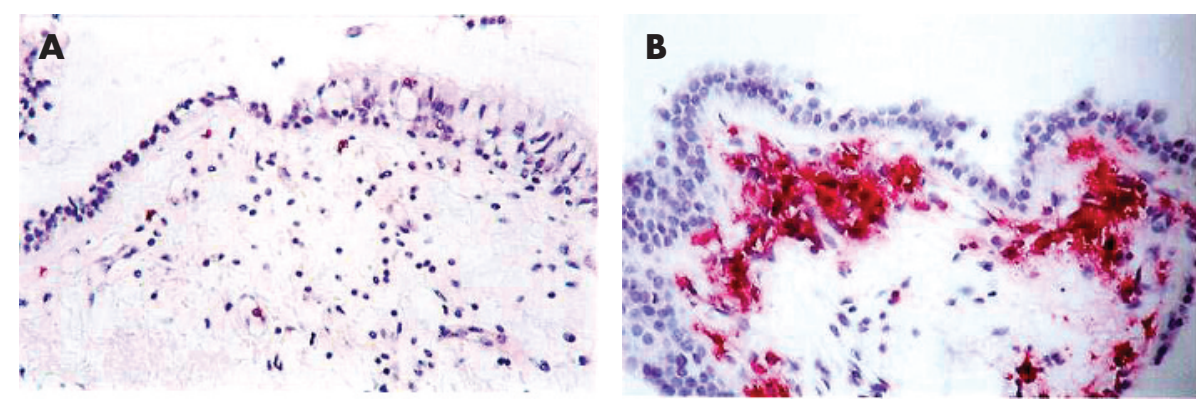

Figure 1 Neutrophil elastase positivity in the airway mucosa of (A) a patient with stable asthma and (B) a patient with a severe exacerbation of asthma. Original magnification $\times 200$. 

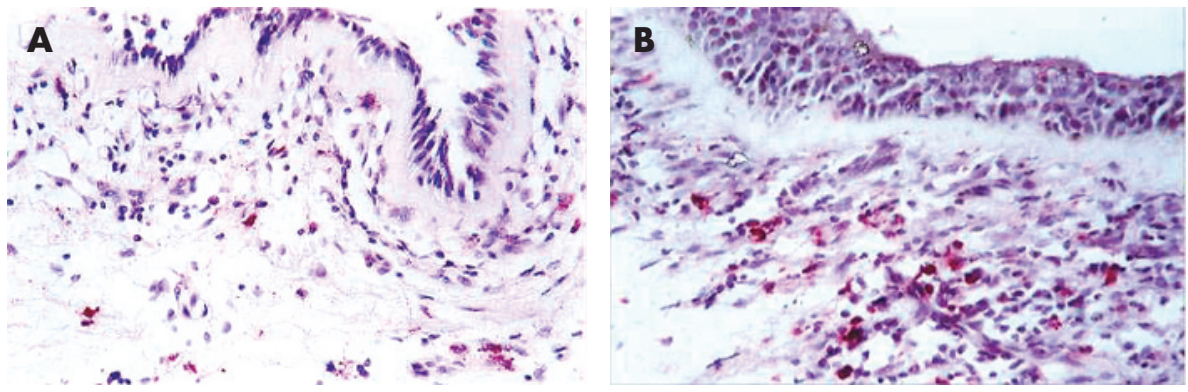

Figure 2 Anti-eosinophil cationic proteinpositive cells in the airway mucosa of $(A)$ a patient with stable asthma and (B) a patient with a severe exacerbation of asthma. Original magnification $\times 200$.
Biosystems Inc, Sunnyvale, California, USA) to maintain consistency of staining across the entire study.

\section{In situ hybridisation}

The technique of in situ hybridisation was applied using riboprobes that detected intracytoplasmic mRNA for the chemokines CXCL5 and CXCL8 and their receptors, CXCR1 and CXCR2, respectively. The preparation of cRNA probes and in situ hybridisation procedures have been described previously. ${ }^{15} 18$

\section{Quantification and data analysis}

The slides were coded to avoid observer bias. Measurements of epithelial and subepithelial areas and the thickness of the reticular basement membrane (RBM) were made with an image analysis system comprising a light microscope (Zeiss, Germany), a JVC video camera and an Apple Macintosh computer using Image analysis 1.55 software (Apple Mac, Cupertino, CA, USA). The thickness of the RBM was measured at 35 points along the length of each H\&E-stained tissue section, $20 \mu \mathrm{m}$ apart, as reported previously, ${ }^{19}$ and the geometric mean of all measurements was determined.

Using a light microscope (Dialux 20, Leitz, Wetzlar, Germany) at $\times 400$ magnification, area profile counts were used to count neutrophils and eosinophils in the epithelial and subepithelial areas of each biopsy specimen. The data were calculated and presented as positive cells $/ \mathrm{mm}^{2}$ tissue, the mean of all evaluable biopsy specimens representing the value for that subject. The same method was used for counting in situ hybridisation positive cells in the subepithelium, but the point counting technique was used to measure mRNA gene expression for CXCL5, CXCL8, CXCR1 and CXCR2 in the epithelium because of the diffuse expression of the mRNA over areas of epithelium. With an eyepiece graticule containing 100 equidistant points, the points over both mRNA positive and negative epithelial areas for each of the genes of interest were counted.
The data were calculated and presented as a percentage of the epithelial area that was positive. ${ }^{15} 20$

\section{Statistical analyses}

Data for the percentage of positive epithelial areas and the thickness of the RBM for each group were normally distributed and expressed as mean (SE). ANOVA followed by Student's $t$ tests were applied to test for differences between the three groups. The data for cell counts were non-normally distributed and expressed as median (range) positive cells $/ \mathrm{mm}^{2}$ epithelial and subepithelial areas. Kruskal-Wallis tests followed by Mann-Whitney U tests were applied to test for differences between the patient groups. Spearman rank correlation was used to determine the association between parameters. A p value of $<0.05$ was accepted as statistically significant in both the $t$ test and the Mann-Whitney U test. For the Spearman rank correlation, a Bonferonni correction for multiple comparisons (ie, 5) was applied and a p value of $\leqslant 0.03$ was used as the threshold for statistical significance. The statistical package StatView 5 (SAS Institute Inc, North Carolina, USA) was used for all the statistical analyses.

\section{RESULTS}

\section{Clinical findings}

Table 1 summarises the demographic characteristics of the subjects. The S-asthma group was significantly younger than the NSC or E-asthma groups $(\mathrm{p}<0.0001$ for each). Both the $\mathrm{FEV}_{1} \%$ predicted and $\mathrm{FEV}_{1} / \mathrm{FVC}$ values of the E-asthma group were significantly lower than those of the NSC and S-asthma groups $(\mathrm{p}<0.0001$ for both).

\section{Biopsy quality and RBM thickness}

Endobronchial biopsies were $1-2 \mathrm{~mm}$ in diameter and of good quality (that is, evaluable), as defined by adequate length of RBM $(>1 \mathrm{~mm})$ and subepithelium area $\left(>0.6 \mathrm{~mm}^{2}\right)$ excluding

Table 2 Counts of neutrophil elastase (NE)+ and anti-eosinophil cationic protein (EG2)+ cells per $\mathrm{mm}^{2}$ epithelium and subepithelium

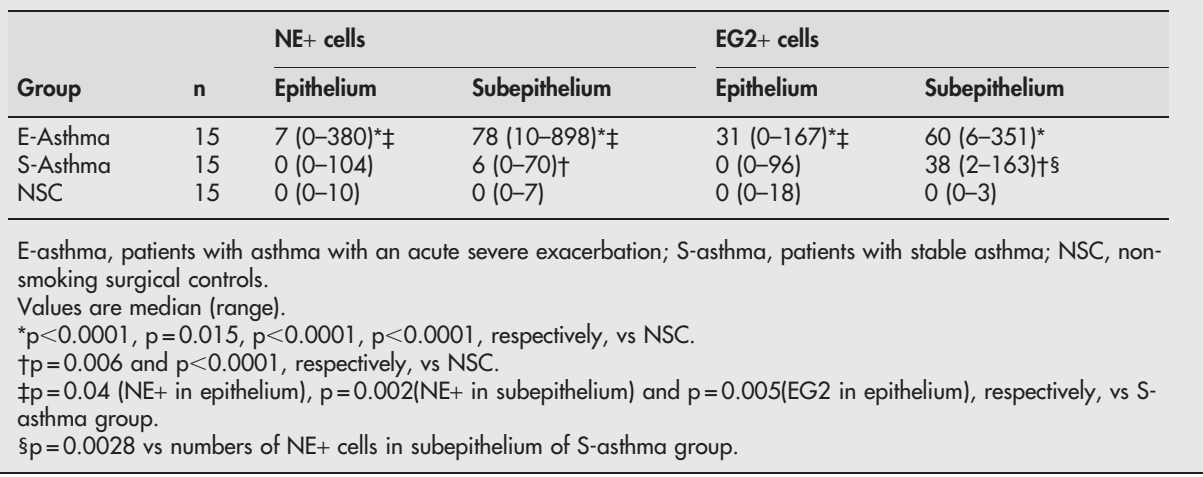




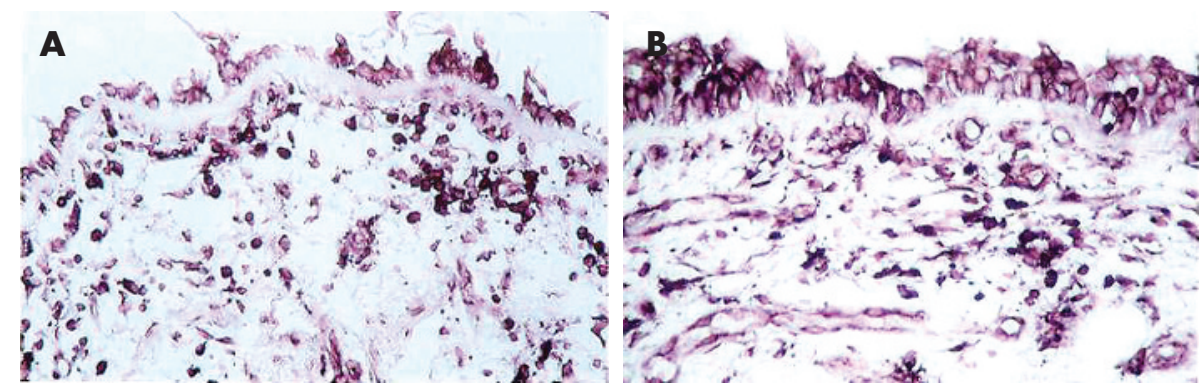

Figure 3 In situ hybridisation for $\mathrm{CXCL5}$ mRNA gene expression: strongly positive cells in the airway mucosa from (A) a patient with stable asthma and (B) a patient with a severe exacerbation of asthma. Original magnification $\times 200$.

muscle, gland, haemorrhage or oedema. All evaluable bronchial biopsy specimens from each patient were included and the average for each patient was used in the analysis. The mean (SE) thickness of the RBM in the E-asthma group (9.9 $(0.5) \mu \mathrm{m})$ and the S-asthma group $(6.8(0.4) \mu \mathrm{m})$ was greater than in the NSC group $(4.3(0.1) \mu \mathrm{m}$, both $\mathrm{p}<0.0001)$, and these differences were consistent with the clinical diagnosis of asthma. Moreover, the RBM of the E-asthma group was thicker than that of the $S$-asthma group $(p=0.0007)$.

\section{Neutrophilia and eosinophilia}

Neutrophils and eosinophils were identified in both the epithelium and subepithelium of the bronchial mucosa in the two asthma groups (figs 1 and 2 and table 2). The numbers of epithelial and subepithelial neutrophils and eosinophils were greater in the E-asthma group than in the NSC group (table 2), and the numbers of neutrophils were much greater in both the epithelium and subepithelium of the E-asthma group than in the S-asthma group. Although there were more subepithelial eosinophils in the E-asthma group than in the S-asthma group, the difference was only significant for the epithelium. The number of eosinophils in the subepithelium of the S-asthma group was more than six times higher than the number of neutrophils ( $p=0.002$, table 2 ). In contrast, in the E-asthma group the numbers of subepithelial neutrophils and eosinophils were broadly similar.

\section{Gene expression}

Cells expressing CXCL8, CXCL5, CXCR1 and CXCR2 mRNA were found in both surface epithelial and subepithelial compartments. CXCL5 mRNA was the most strongly expressed in the mucosa of both groups of patients with asthma (fig $3 \mathrm{~A}$ and B). The intensity of gene expression for CXCR2 mRNA (fig 4A and B) was stronger than that of CXCRI across the groups. The percentages of epithelial area positive for these genes are shown in table 3. Significantly greater areas of the epithelium expressed these genes in the E-asthma and Sasthma groups than in the NSC group. Moreover, the percentage of epithelium expressing CXCL5 and CXCR2 was further increased by comparison with that of the S-asthma group $(p=0.03$ and $p=0.01$, respectively). The percentages of the epithelium expressing CXCL5 and CXCR2 were greater than that of CXCL8 and CXCRI in both the E-asthma and S-asthma groups, respectively $(\mathrm{p}<0.0001$ for CXCL5, $\mathrm{p}=0.0009$ and $\mathrm{p}=0.0014$ for CXCR2, respectively).

The numbers of subepithelial inflammatory cells expressing CXCL5, CXCL8, CXCR1 and CXCR2 are shown in fig 5A-D. In the E-asthma group the numbers were significantly greater than in the NSC group $(p<0.0001, p=0.009, p=0.0004$ and $\mathrm{p}<0.0001$, respectively), and the numbers of CXCL5+, CXCL8+, CXCR2+ cells in the $S$-asthma group were significantly greater than in the NSC group $(\mathrm{p}=0.0003, \mathrm{p}=0.001$ and $\mathrm{p}=0.004$, respectively). Only CXCR2 mRNA-positive cells were significantly greater in the E-asthma group than in the S-asthma group $(\mathrm{p}=0.01)$.

In the E-asthma group the number of cells expressing CXCL5 (median 259 (range 85-797)) was similar to the number of CXCR2 mRNA-positive cells (median 236 (range 185-1055)), but CXCL5 and CXCR2 were eightfold and 2.5 -fold greater than that of CXCL8 (32 (range 0-62)) and CXCRl (93 (range 9332)) mRNA-positive cells, respectively $(p=0.0001$ and $\mathrm{p}<0.0001$, respectively). Similarly, there were greater numbers of CXCL5 (201 (range 22-577)) and CXCR2 (136 (range 0466)) than CXCL8 (28 (range 2-103)) and CXCR1 (61 (range 2149)), respectively, in the S-asthma group.

\section{Correlations}

In the E-asthma group no statistically significant correlations were found between the numbers of neutrophils and any other parameter measured, but there were significant correlations between eosinophil counts and those expressing either CXCL5 or CXCR2 mRNA $(\mathrm{r}=0.53, \mathrm{p}=0.02$ and $\mathrm{r}=0.57, \mathrm{p}=0.03$, respectively; fig $6 \mathrm{~A}$ and $\mathrm{B}$ ). In the $\mathrm{S}$-asthma group significant correlations were found only between counts of CXCRl and CXCR2 mRNA-positive cells $(\mathrm{r}=0.61, \mathrm{p}=0.02)$. There was no significant association between the length of intubation and the numbers of neutrophils or eosinophils in the E-asthma group.

\section{DISCUSSION}

This is the first study to examine the bronchial mucosa directly in patients with a severe exacerbation of asthma. We found increased numbers of mucosal neutrophils and of cells
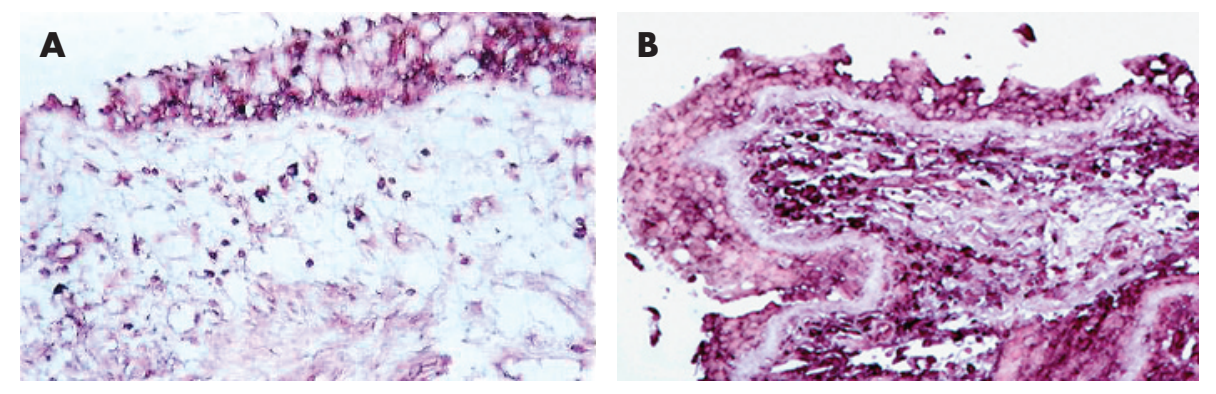

Figure 4 In situ hybridisation for CXCR2 mRNA-positive cells in the airway mucosa of (A) a patient with stable asthma and (B) a patient with a severe exacerbation of asthma. Original magnification $\times 200$. 
Table 3 Percentage of epithelium expressing mRNA for CXCL5, CXCL8, CXCR1 and CXCR2

\begin{tabular}{llllll}
\hline Group & $\mathbf{n}$ & CXCL5+ cells & CXCL8+ cells & CXCR1+ cells & CXCR2+ cells \\
\hline E-asthma & 15 & $81(5.4)^{*} \dagger \neq$ & $22(3.5)^{*}$ & $34(4.3)^{*}$ & $58(4.8)^{*} \dagger \S$ \\
S-asthma & 15 & $64(5.1)^{*} \ddagger$ & $28(3.3)^{*}$ & $34(4.6)^{*}$ & $40(5.3)^{\star} \S$ \\
NSC & 15 & $6(2.2)$ & $0.6(0.4)$ & $2(1.4)$ & $5(2.5)$ \\
\hline
\end{tabular}

E-asthma, patients with asthma with an acute severe exacerbation; S-asthma, patients with stable asthma; NSC, non-smoking surgical controls.

Values are mean (SE)

* $\mathrm{p}<0.0001$ vs NSC.

$\mathrm{tp}=0.03(\mathrm{CXCL5})$ and $\mathrm{p}=0.01(\mathrm{CXCR} 2)$ vs S-asthma

$\neq \mathrm{p}<0.0001$ vs CXCL8+ cells.

$\S p=0.0009$ (E-asthma) and $p=0.001$ (S-asthma) vs $C X C R 1+$ cells

expressing the genes for neutrophil chemoattractants CXCL5, CXCL8 and their receptors CXCR1 and CXCR2. Thus, in severe exacerbations of asthma, the disproportionately greater increase in neutrophils resulted in approximately equal tissue densities of neutrophils and eosinophils. Interestingly, the numbers of mucosal CXCL5 or CXCR2 mRNA-positive inflammatory cells were positively correlated with the number of subepithelial eosinophils rather than, as anticipated, neutrophils.

Bronchial mucosal tissue in stable mild to moderate asthma is characterised by an influx of eosinophils and CD4+ T lymphocytes, whereas neutrophils are usually sparse. ${ }^{21}$ Our patient group with mild stable asthma had the usual predominance of eosinophils but, in contrast to our previous reports, we found a slight but significant increase in the numbers of mucosal neutrophils compared with the control group. Yet, the patients admitted to hospital for a severe exacerbation of their asthma had a large (13-fold) mucosal accumulation of neutrophils, to the extent that their greater number roughly matched that of eosinophils. Thus, the final neutrophil to eosinophil ratio increased from an average of 1:6 in S-asthma to $1: 1$ in E-asthma, which was almost entirely due to the larger number of neutrophils.

The very modest rise in eosinophils in an asthma exacerbation is in agreement with the findings of others. ${ }^{9}$ Thus, in contrast to stable asthma, in a severe exacerbation the eosinophil is no longer the predominant effector inflammatory cell which is in agreement with findings in sputum studied in mild exacerbations of asthma, ${ }^{5}$ in therapeutic bronchial lavage in patients in status asthmatics, ${ }^{22}$ and in sputum, ${ }^{6}$ lavage fluid
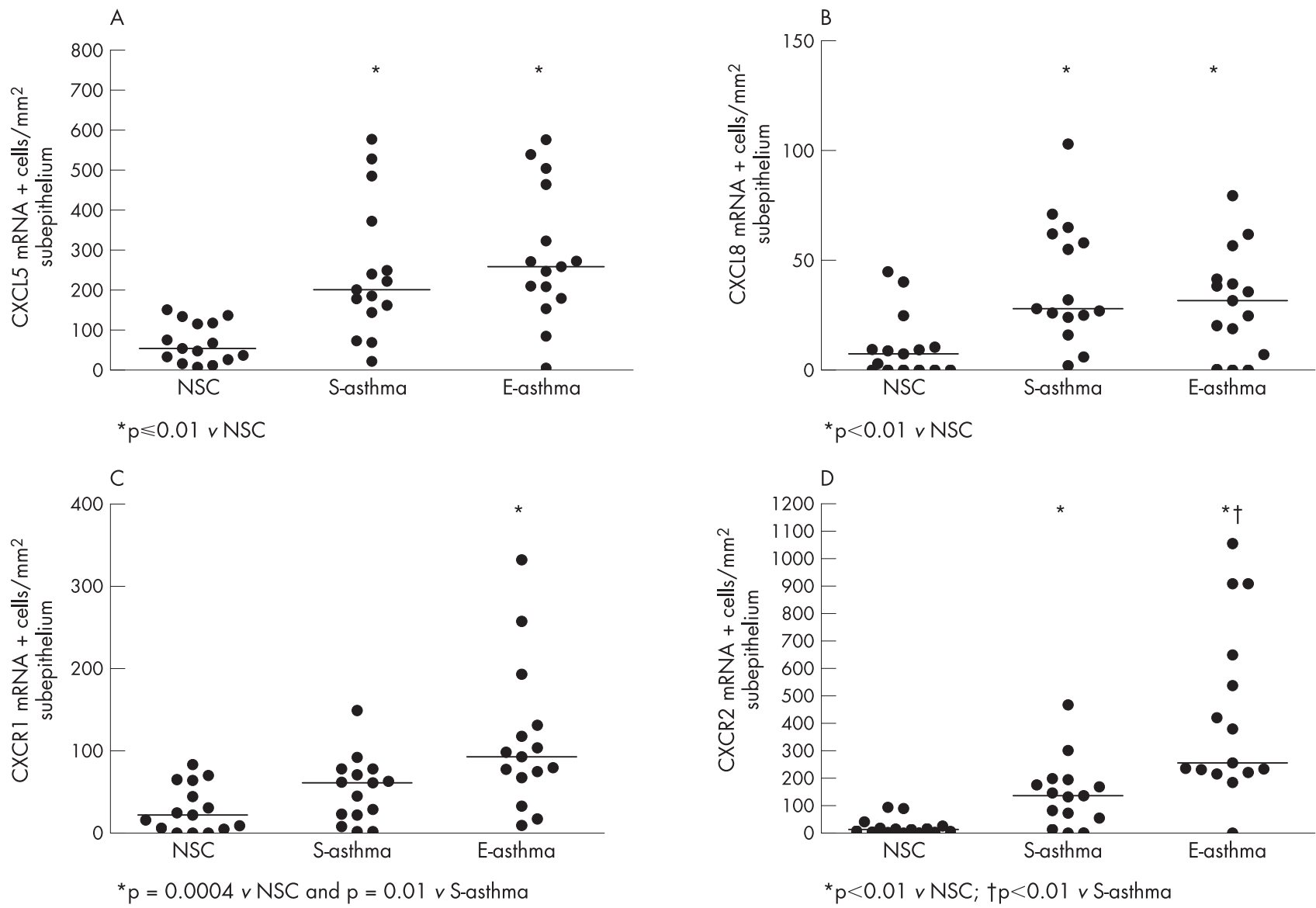

Figure 5 Counts of (A) CXCL5 mRNA-positive cells, (B) CXCL8 mRNA-positive cells, (C) CXCR1 mRNA-positive cells and (D) CXCR2 mRNA-positive cells in the subepithelium of biopsy specimens taken from non-atopic non-smoker surgical control subjects (NSC) and patients with stable asthma (S-asthma) and those with asthma with an acute severe exacerbation (E-asthma). Horizontal bars represent median values. 

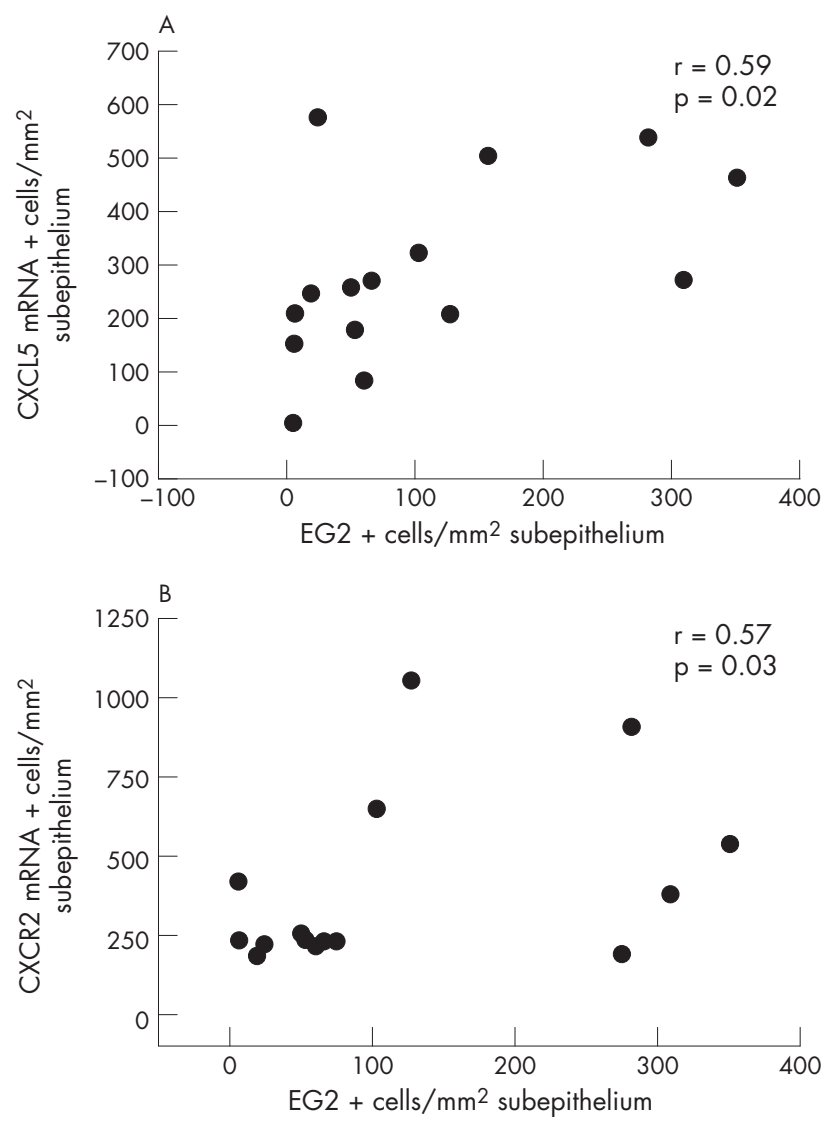

Figure 6 Correlation between anti-eosinophil cationic protein (EG2)+ cells and (A) CXCL5 mRNA-positive cells and (B) CXCR2 mRNA-positive cells in the subepithelium of patients admitted to hospital with a severe asthma exacerbation (E-asthma group).

and bronchial tissue of patients with ongoing chronic severe asthma. ${ }^{23}$ These findings underline the need to understand the mechanism(s) of such neutrophil recruitment.

It is known that neutrophil recruitment and tissue accumulation are due, in part, to chemoattraction by neutrophil chemokines including CXCL8 and CXCL5 via the actions on cell surface receptors, specifically CXCR1 and CXCR2. ${ }^{11-14}$ In both stable and severe exacerbations of asthma, the numbers of cells expressing CXCL5 or CXCR2 genes were approximately eightfold and threefold more than those expressing CXCL8 and CXCRl, respectively. By comparison with stable asthma, the extent of CXCR2 upregulation was much greater in severe exacerbations of asthma, with the number of cells expressing CXCR2 far in excess of the numbers of neutrophils per se. This indicates that cells other than neutrophils express CXCR2 in exacerbations of asthma, and these probably include monocytes and mast cells as well as eosinophils. ${ }^{24} 25$

Unexpectedly, and unlike our previous findings in COPD, ${ }^{15}$ there was no significant association between neutrophils and neutrophil chemoattractants in the present study of E-asthma. Interestingly, our data show upregulation of CXCL5 and CXCR2 that correlate instead with the larger numbers of eosinophils found in the E-asthma group. It appears, therefore, that the receptors and chemoattractants normally associated with recruitment of neutrophils may also be involved in the recruitment of eosinophils and other inflammatory cell phenotypes important in severe exacerbations of asthma.

These data are relevant to the recent drive to develop treatment centred on CXC receptor blockade. ${ }^{24} 26-28$ In addition,
CXCL5 has been thought of as an important mediator of lung injury $^{629-31}$ and is associated with allergic airway disease. ${ }^{32}$ Through expression of CXCL5, eosinophils can recruit and activate CXCR2-bearing cells such as neutrophils to sites of inflammation. ${ }^{25}$ We have shown here in E-asthma and previously in $\mathrm{E}-\mathrm{COPD}^{15}$ that the surface epithelium is likely to be a major source of mucosal CXCL5. While we acknowledge that the relationship between mRNA expression and protein production for CXCL5 may not be linear, release of the protein would act as a chemoattractant for both circulating neutrophils and eosinophils. By comparison with CXCL8, the relative importance of CXCL5 is now more widely recognised. ${ }^{33} \mathrm{~A}$ recent study suggested that there was downregulation of CXCR2 on neutrophils after their recruitment to the airway wall. ${ }^{35}$ However, our data show that the numbers of cells expressing CXCR1 and CXCR2 as well as neutrophils and eosinophils in exacerbations of asthma are greater than normal.

\section{Limitations of the study}

We considered it reasonable to seek permission to sample the airway mucosa directly by endobronchial biopsy for the purpose of research in patients being intubated as an emergency treatment for the management of a severe exacerbation. The ethical committee concluded that, as the additional risk was small, the potential long-term benefits from the study would outweigh any additional risk, providing there was informed and signed written consent from surrogates and that the procedures were only carried out in a hospital setting by an experienced team. These conditions were met.

This study was not age-matched with regard to the S-asthma group. The original intention was to make comparisons with our previous E-COPD patients, average age $>50$ years (however, these data are now already published ${ }^{15}$ ). Thus, older rather than younger patients had been chosen for the E-asthma group. Furthermore, since most of the subjects in the E-asthma group were women, it has been suggested that the frequency of their exacerbations may be influenced by hormonal factors. It is known that premenopausal women experience a reduction in pulmonary function and an increase in asthma exacerbations and in hospital admissions. ${ }^{36}$ However, since most of the patients in the E-asthma group were postmenopausal, it is likely that they would have had fewer exacerbations than younger female patients.

Weak and variable associations have been reported between the time of mechanical ventilation and extent of neutrophilia. ${ }^{22}{ }^{37-39}$ However, we did not find such an association and do not therefore consider that the effects of intubation per se confounded our interpretation.

Patients in the E-asthma group were given large doses of parenteral steroids during their hospital admission. A relationship between neutrophil accumulation and steroid treatment has been advanced and debated. ${ }^{23}{ }^{40}$ Lamblin et al ${ }^{22}$ suggested that neutrophil recruitment was more likely to be the result of an inflammatory cascade initiated by airway injury than the result of steroid treatment. In our study, one patient with severe asthma had not taken steroid medication before admission to hospital and this patient had a lower neutrophil count than the average for the E-asthma group ( $10 \mathrm{vs} 78 / \mathrm{mm}^{2}$ ). However, three patients who had had steroid treatment had even fewer neutrophils than the aforementioned patient. It is therefore difficult to argue that the marked increase in neutrophils in the E-asthma group was the result of steroid treatment alone.

Finally, it is now widely recognised that respiratory viral infections are an important cause of asthma exacerbations in children and adults, ${ }^{41}$ and are a determinant of airway neutrophilia in exacerbations of both asthma and COPD. ${ }^{52-45}$ 
Moreover, a recent in vitro study showed that rhinovirus infection induces bronchial epithelial neutrophil chemokine CXCL5 and CXCL8 production. ${ }^{46}$ The present study did not aim to evaluate the role of infection in recruiting airway neutrophils, and we acknowledge that it would be worthwhile to try to address this in follow-up investigations.

In conclusion, in patients with a severe exacerbation of asthma, we found an increase in the numbers of neutrophils, eosinophils and cells expressing the chemoattractants CXCL5 and CXCL8 and their receptors CXCR1 and CXCR2. CXCL5 and CXCR2 are especially prominent and are associated with the eosinophilia of E-asthma. In contrast to E-COPD, where neutrophils clearly predominate, ${ }^{15}$ the number of neutrophils in E-asthma is balanced by approximately equal numbers of tissue eosinophils. New treatments that target the CXCR2/ CXCL5 axis are likely to be an effective way of modulating the numbers of polymorphonuclear inflammatory cells associated with severe exacerbations of asthma.

\section{ACKNOWLEDGEMENTS}

The authors thank GSK for supplying the receptor probes.

\section{Authors' affiliations}

Yusheng Qiu, Jie Zhu, Peter K Jeffery, Lung Pathology, Department of Gene Therapy, Imperial College, Royal Brompton Hospital, London, UK Venkata Bandi, Kay K Guntupalli, Department of Medicine, Baylor College of Medicine, Ben Taub General Hospital, Houston, Texas, USA

This study was supported by the National Institutes of Health, USA and Lung Pathology departmental funds.

Competing interests: None.

\section{REFERENCES}

1 Cochrane GM, Jackson WF, Rees PJ. Epidemiology of asthma. In: Cochrane GM, Jackson WF, Rees PJ, eds. Asthma:current perspectives. London: Mosby-Wolfe, 2001:5-16.

2 Jeffery PK. Immunopathology: comparison of COPD and asthma. In: Hansel T,, Barnes PJ, eds. New drugs for asthma, allergy and COPD. Basel: Karger, 2001:24-9.

3 Barnes PJ. Mechanisms in COPD: differences from asthma. Chest 2000;117:10-4S

4 Jeffery PK. Comparison of the structural and inflammatory features of COPD and asthma. Chest 2000;117:251-60s.

5 Fahy JV, Kim KW, Liu J, et al. Prominent neutrophilic inflammation in sputum from subjects with asthma exacerbation. J Allergy Clin Immunol 1995;95:843-52

6 Jatakanon A, Uasuf C, Maziak W, et al. Neutrophilic inflammation in severe persistent asthma. Am J Respir Crit Care Med 1999;160:1532-9.

7 Ordonez $\mathrm{CL}$, Shaughnessy TE, Matthay MA, et al. Increased neutrophil numbers and IL-8 levels in airway secretions in acute severe asthma. Clinical and biologic significance. Am J Respir Crit Care Med 2000;161:1185-90.

8 Douwes J, Gibson P, Pekkanen J, et al. Non-eosinophilic asthma: importance and possible mechanisms. Thorax 2002;57:643-8.

9 Castro M, Bloch SR, Jenkerson MV, et al. Asthma exacerbations after glucocorticoid withdrawal reflects T cell recruitment to the airway. Am J Respir Crit Care Med 2004;169:842-9

10 Louis $\mathbf{R}$, Lau LC, Bron AO, et al. The relationship between airways inflammation and asthma severity. Am J Respir Crit Care Med 2000;161:9-16.

11 Wuyts A, Proost P, van Damme J. Interleukin-8 and other CXC chemokines. In: Thomson A, eds. The cytokine handbook.3rd ed. San Diego: Academic Press, 2001:271-311.

12 Imaizumi T, Albertine $\mathrm{KH}$, Jicha DL, et al. Human endothelial cells synthesize ENA-78: relationship to IL-8 and to signaling of PMN adhesion. Am J Respir Cell Mol Biol 1997; 17:181-92.

13 Lee J, Horuk R, Rice GC, et al. Characterization of two high affinity human interleukin-8 receptors. J Biol Chem 1992;267:16283-7.

14 Chuntharapai A, Kim KJ. Regulation of the expression of IL-8 receptor A/B by IL8: possible functions of each receptor. J Immunol 1995;155:2587-94.

15 Qiu Y, Zhu J, Bandi V, et al. Biopsy neutrophilia, neutrophil chemokine and receptor gene expression in severe exacerbations of chronic obstructive pulmonary disease. Am J Respir Crit Care Med 2003;168:968-75.

16 Zhu J, Qiu Y, Figueroa DJ, et al. Localization and upregulation of cysteinyl leukotriene-1 receptor in asthmatic bronchial mucosa. Am J Respir Cell Mol Biol 2005;33:531-40.
17 Clark TJH, Cagnani CB, Bousquet J, et al. Global strategy for asthma management and prevention, NHLBI/WHO Workshop Report. Bethesda, Maryland: NIH, 2002.

18 Zhu J, Qiu YS, Majumdar S, et al. Exacerbations of bronchitis: bronchial eosinophilia and gene expression for IL-4, IL-5, and eosinophil chemoattractants in bronchitis. Am J Respir Crit Care Med 2001;164:109-16.

19 Sullivan P, Stephens D, Ansari T, et al. Variation in the measurements of basement membrane thickness and inflammatory cell number in bronchial biopsies. Eur Respir J 1998;12:811-5.

20 Zhu J, Kilty I, Granger H, et al. Gene expression and immunolocalization of 15 lipooxygenase isozymes in the airway mucosa of smokers with chronic bronchitis. Am J Respir Cell Mol Biol 2002;27:666-77

21 Azzawi M, Bradley B, Jeffery PK, et al. Identification of activated T lymphocytes and eosinophils in bronchial biopsies in stable atopic asthma. Am Rev Respir Dis 1990:142:1407-13.

22 Lamblin C, Gosset P, Tillie-Leblond I, et al. Bronchial neutrophilia in patients with noninfectious status asthmaticus. Am J Respir Crit Care Med 1998; 157:394-402.

23 Wenzel SE, Szefler SJ, Leung DYM, et al. Bronchoscopic evaluation of severe asthma. Persistent inflammation associated with high dose glucocorticoids. Am J Respir Crit Care Med 1997;156:737-43.

24 Owen C. Chemokine receptors in airway disease: which receptors to target? Pulm Pharmacol Ther 2001;14:193-202.

25 Persson T, Monsef N, Andersson P, et al. Expression of the neutrophil-activating CXC chemokine ENA-78/CXCL5 by human eosinophils. Clin Exp Allergy 2003;33:531-7

26 Hansel TT, Barnes PJ. Novel drugs for treating asthma. Curr Allergy Asthma Rep 2001;1:164-73.

27 Barnes PJ, Hansel TT. Prospects for new drugs for chronic obstructive pulmonary disease. Lancet 2004;364:985-96

28 Podolin PL, Bolognese BJ, Foley JJ, et al. A potent and selective nonpeptide antagonist of CXCR2 inhibits acute and chronic models of arthritis in the rabbit. $J$ Immunology 2002;169:6435-44

29 Goodman RB, Strieter RM, Martin DP, et al. Inflammatory cytokines in patients with persistence of the acute respiratory distress syndrome. Am J Respir Crit Care Med 1996; 154:602-11

30 Colletti LM, Kunkel SL, Walz A, et al. Chemokine expression during hepatic ischemia/reperfusion-induced lung injury in the rat. The role of epithelial neutrophil activating protein. J Clin Invest 1995;95:134-41.

31 Keane MP, Belperio JA, Burdick MD, et al. ENA-78 is an important angiogenic factor in idiopathic pulmonary fibrosis. Am J Respir Crit Care Med $2001 ; 164: 2239-42$.

32 Lukacs NW, Hogaboam CM, Kunkel SL, et al. Mast cells produce ENA-78, which can function as a potent neutrophil chemoattractant during allergic airway inflammation. J Leukoc Biol 1998;63:746-51

33 Bisset LR, Schmid-Grendelmeier P. Chemokines and their receptors in the pathogenesis of allergic asthma: progress and perspective. Curr Opin Pulm Med 2005; 11:35-42.

34 Donninger H, Glashoff R, Haitchi HM, et al. Rhinovirus induction of the CXC chemokine epithelial-neutrophil activating peptide-78 in bronchial epithelium. $J$ Infect Dis 2003;187:1809-17.

35 Pignatti P, Moscato G, Casarini S, et al. Downmodulation of CXCL8/IL-8 receptors on neutrophils after recruitment in the airways. J Allergy Clin Immunol 2005; 115:88-94.

36 Haggerty CL, Ness RB, Kelsey S, et al. The impact of estrogen and progesterone on asthma. Ann Allergy Asthma Immunol 2003:90:284-91.

37 Delclaux C, D'Ortho MP, Delacourt C, et al. Gelatinases in epithelial lining fluid of patients with adult respiratory distress syndrome. Am J Physiol 1997;272:L442-51

38 Tillie-Leblond I, Pugin J, Marquette $\mathrm{CH}$, et al. Balance between proinflammatory cytokines and their inhibitors in bronchial lavage from patients with status asthmaticus. Am J Respir Crit Care Med 1999;159:487-94.

39 McNamara PS, Flanagan BF, Baldwin LM, et al. Interleukin 9 production in the lungs of infants with severe respiratory syncytial virus bronchiolitis. Lancet 2004:363:1031-37.

40 Cox G. Glucocorticoid treatment inhibits apoptosis in human neutrophils: separation of survival and activation outcomes. J Immunol 1995;154:4719-25.

41 Pattemore PK. Epidemiology and diagnosis of virus-induced asthma exacerbations. In: Johnston SL, Papadopoulos NG, eds. Respiratory infection in allergy and asthma.Lung Biology in Health and Disease. New York: Marcel Dekke Inc, 2003;178:43-89.

42 Aaron SD, Angel JB, Lunau $M$, et al. Granulocyte inflammatory markers and airway infection during acute exacerbation of chronic obstructive pulmonary disease. Am J Respir Crit Care Med 2001;163:349-55.

43 Seemungal T, Harper-Owen R, Bhowmik A, et al. Respiratory viruses, symptoms, and inflammatory markers in acute exacerbations and stable chronic obstructive pulmonary disease. Am J Respir Crit Care Med 2001; 164:1618-23.

44 Seemungal TA, Harper-Owen R, Bhowmik A, et al. Detection of rhinovirus in induced sputum at exacerbation of chronic obstructive pulmonary disease. Eur Respir J 2000; 16:677-83.

45 Atmar RL, Guy E, Guntupalli KK, et al. Respiratory tract viral infections in inner city asthmatic adults. Arch Intern Med 1998;158:2453-9.

46 Edwards MR, Johnson MW, Johnston SL. Combination therapy: synergistic suppression of virus induced chemokines in airway epithelial cells. Am J Respir Cell Mol Biol 2006;34:616-24. 